\title{
High-Rate Algae Pond Coupled with Polyester Fiber Strips for Organics and Nutrient Removal in a Cold Climate
}

\author{
Yi Ding ${ }^{1,2}$, Yuhui Wang ${ }^{2}$, Xingpo Liu ${ }^{1}$, Xinshan Song ${ }^{2}$, Daolun Feng ${ }^{*}$ \\ ${ }^{1}$ College of Ocean Science and Engineering, Center for Marine Environmental and Ecological Modelling, \\ Shanghai Maritime University, Shanghai, China \\ ${ }^{2}$ College of Environmental Science and Engineering, State Environmental Protection Engineering Center for Pollution \\ Treatment and Control in the Textile Industry, Donghua University, Shanghai, China
}

Received: 28 June 2018

Accepted: 7 October 2018

\begin{abstract}
Algae growth and photosynthesis can be inhibited in high-rate algae ponds (HRAP) in cold climates. This study evaluated the feasibility and importance of polyester fiber strips (PFS) that can be applied to HRAP as growing sites for algae survival, thus enhancing HRAP performance. The results indicated that $42.0 \pm 2.0 \% \mathrm{TN}, 86.0 \pm 1.0 \% \mathrm{TP}$ and $99.0 \pm 1.0 \%$ DCOD were reduced in HRAP with high PFS amounts, which outperformed HRAP with low PFS amounts and was significantly higher than control. The positive role of PFS on algae biomass production could effectively remove organics and nutrient from wastewater.
\end{abstract}

Keywords: high-rate algae pond, polyester fiber strip, cold climate, organics and nutrient removal

\section{Introduction}

Algae can help remove organics and nutrient (N, P) from wastewater [1-2]. High-rate algae ponds (HRAP) are an efficient and inexpensive technology for algae biomass production, and in which a large quantity of wastewater can be treated [3]. Algae growth is considerably influenced by climatic conditions, particularly temperature [4-5]. Low temperature restrains algae photosynthetic activities and reduces algae growth, resulting in low purification efficiency. The main objective of HRAP is to prevent algae loss

*e-mail: dlfeng@shmtu.edu.cn for efficient removal of multi-pollutants. However, slow growth and survival rate under cold climate usually causes algae loss, thus affecting HRAP performance [6]. An important aspect in improving HRAP performance is finding a cost-effective and sustainable method for increasing algae biomass.

It is well known that polyester fiber has excellent biocompatibility and bio-binding capacities [7]. Polyester-fiber strips (PFS) slung up in HRAP can provide void spaces and growing sites for algae growth and survival under cold conditions; in addition, PFS also provide large interfaces for supporting biological and biochemical reaction to clean up the wastewater. Due to structural properties, PFS might improve HRAP performance under cold climate, which has not been investigated to date. 
The objective of this study was to identify the role and amount of PFS on algae biomass and pollutant removal in HRAP. The results of this study were conducive to enhancing our understanding of HRAP design and treatment performance in cold climates, and it might provide significant implications for effective operation of HRAP in cold climates.

\section{Material and Methods}

PFS were slung up into a lab-scale HRAP via transparent polycarbonate pipes (Fig. 1). The dimension of each strip is $60 \mathrm{~cm}$ in length, $6 \mathrm{~cm}$ in width and $2 \mathrm{~cm}$ in thickness. PFS were fed with the algae (Microcystis aeruginosa) solution in a glass container of $10 \mathrm{~L}$ volume for $72 \mathrm{~h}$, prior to being hung up in HRAP. The algae were cultured and enriched in an artificial climatic chamber with BG culture medium and tap water [8]. The strengthened PFS was packed with algae.

Three lab-scale HRAP systems (namely A, B and C) were constructed with identical dimensions (length: $0.96 \mathrm{~m}$, width: $0.60 \mathrm{~m}$, height: $0.60 \mathrm{~m}$ ) on the campus of Donghua University, located in Shanghai, China $\left(38^{\circ} 39^{\prime} 27^{\prime \prime} \mathrm{N}, 104^{\circ} 04^{\prime} 58^{\prime \prime} \mathrm{E}\right)$. Useful volume of each system was $0.32 \mathrm{~m}^{3}$. A mechanical stirrer was used in each system to mix the wastewater at an average surface velocity of $0.15 \pm 0.03 \mathrm{~m} \mathrm{~s}^{-1}$. The algae used in HRAP were Microcystis aeruginosa and chlorophyll a (Chl-a), and contents were determined as an indicator of algae biomass. The experiments were conducted during the winter (October to February) and operated intermittently with hydraulic retention time (HRT) of $3 \mathrm{~d}$. The climate is classified as monsoon subtropical with cold winters (2 to $15^{\circ} \mathrm{C}$ ).

Three systems were operated under different conditions. PFS hung vertically onto polycarbonate pipes were not emplaced in system A (control), while they were installed at the top of systems B and C. Three polycarbonate pipes were used in system B, while six polycarbonate pipes were used in system C. Each polycarbonate pipe was draped with three PFS. Each system received synthetic wastewater from influent tanks (300 L) via peristaltic pumps at a stable inflow rate of $4.0 \pm 0.2 \mathrm{~L} \mathrm{~min}^{-1}$. The total inflow was $250 \mathrm{~L}$ within $1 \mathrm{~h}$. The parameters of synthetic wastewater were set as follows: ammonia nitrogen $\left(\mathrm{NH}_{4}-\mathrm{N}\right), 23.8 \pm 1.0 \mathrm{mg} \mathrm{L}^{-1}$; total nitrogen $(\mathrm{TN}), 25.0 \pm 1.2 \mathrm{mg} \mathrm{L}^{-1}$; dissolved reactive phosphorus (DRP), $5.22 \pm 0.5 \mathrm{mg} \mathrm{L}^{-1}$; total phosphorus

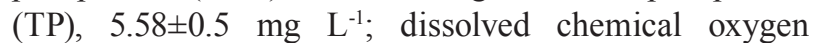
demand (DCOD), $70.0 \pm 5.0 \mathrm{mg} \mathrm{L}^{-1}$; and dissolved oxygen (DO), $4.5 \pm 0.3 \mathrm{mg} \mathrm{L} \mathrm{L}^{-1} ; \mathrm{pH}, 7.5 \pm 0.2$; Chl-a, $20.0 \pm 5.0 \mathrm{mg} \mathrm{L}^{-1}$.

Influent water samples were collected when synthetic wastewater was prepared. Effluent water samples were collected at $6 \mathrm{~h}, 12 \mathrm{~h}, 24 \mathrm{~h}, 30 \mathrm{~h}, 36 \mathrm{~h}, 48 \mathrm{~h}, 54 \mathrm{~h}$, $60 \mathrm{~h}$, and $72 \mathrm{~h}$ to evaluate the variations of Chl-a, $\mathrm{pH}$, DO and pollutant removal of the three systems. Water temperature, $\mathrm{DO}, \mathrm{pH}$, and Chl-a were immediately measured in situ after using a portable water quality multi-probe (Manta 2, EURERA, USA). For $\mathrm{NH}_{4}-\mathrm{N}$, TN, DRP, TP, and DCOD determination with the multiparameter colorimeter (DR900, HACH, USA), the samples were filtered through Whatman GF/C glassfiber filters $(0.22 \mu \mathrm{m})$ for analysis.

All the experiments were performed in triplicate. Statistical functions of Origin 8.0 software (OriginLab, MA, USA) were used to analyze the measurement data. Statistical analyses were performed by Student's $t$ test at $p<0.01$.

\section{Results and Discussion}

Fig. 2 shows the profiles of Chl-a, DO and $\mathrm{pH}$ in HRAP. As observed in Fig. 2a), Chl-a content in PFS systems ( $\mathrm{B}$ and $\mathrm{C}$ ) increased more significantly than in system A (control). The fact that highest Chl-a content of system B (350 mg L-1) was $78 \%$ more than that of system A (197 mg L-1), which indicated that PFS promoted algae growth. In addition, significant differences in Chl-a profile between systems B and

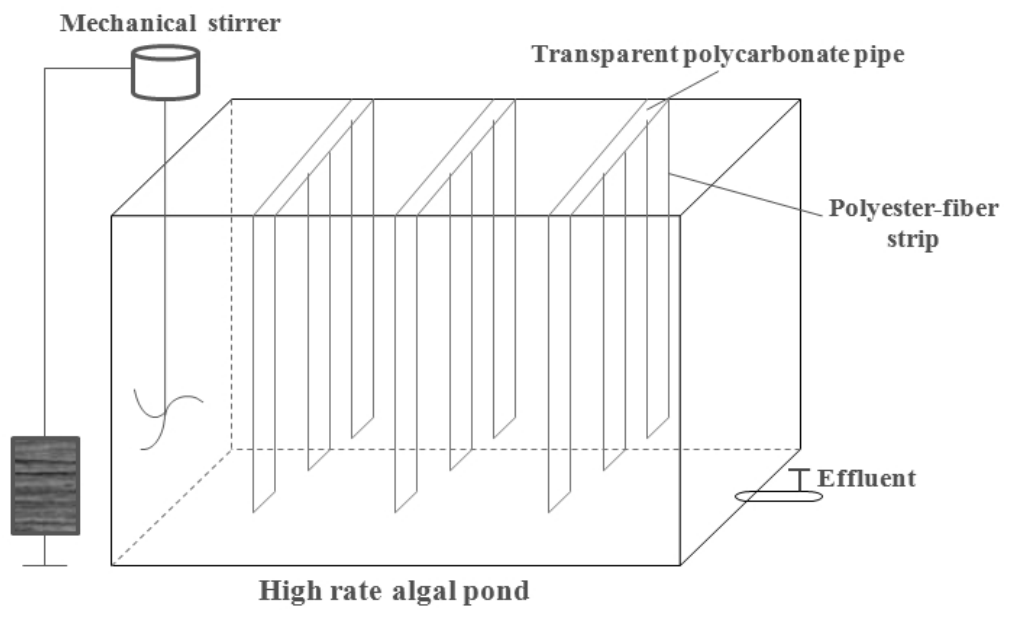

Fig. 1. Schematic diagram of experimental HRAP. 


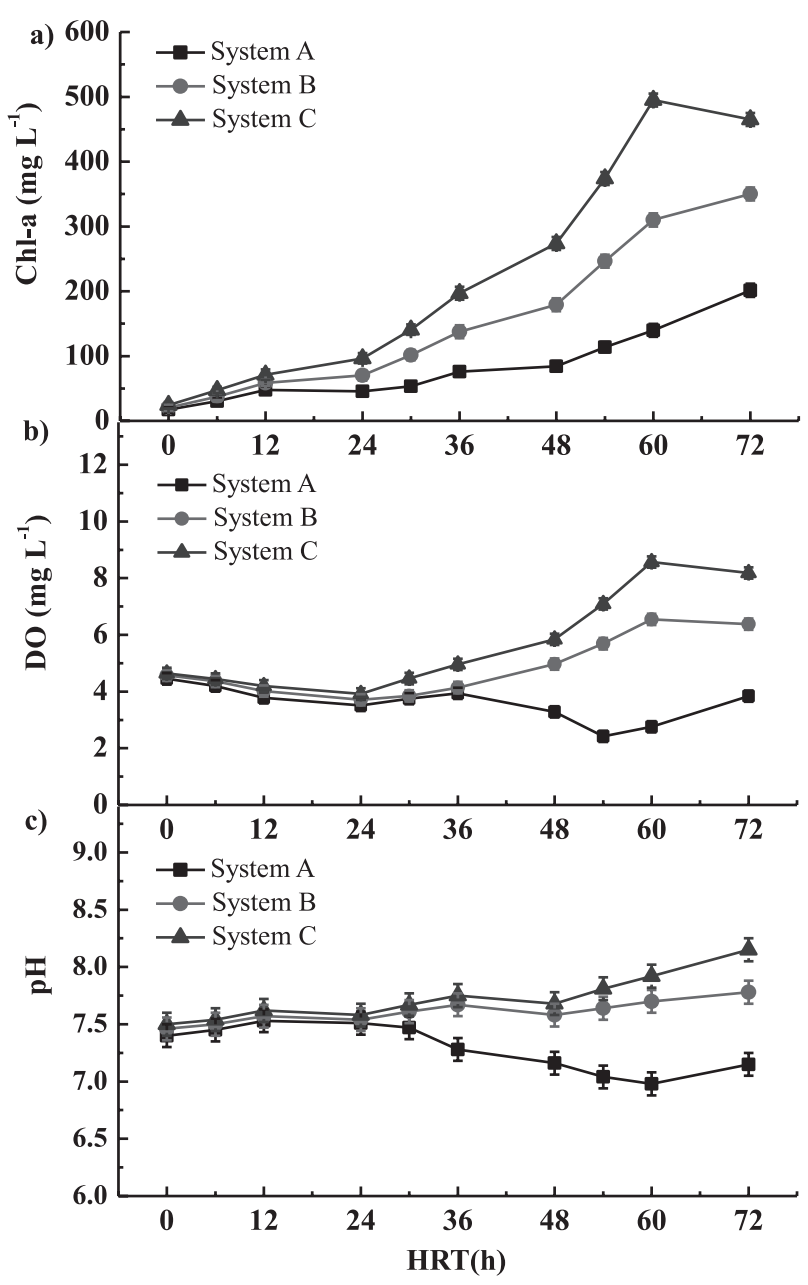

Fig. 2. Profiles of Chl-a a), DO b), and pH c) in HRAP.

C were observed $(p<0.01)$. The algae biomass was higher in system C compared with system B due to the differences in PFS amount. The increasing of PFS amount in HRAP accelerated algae growth.

Algae photosynthesis produces high levels of DO and $\mathrm{pH}$, which fluctuate diurnally [9]. According to Fig. 2b), DO content decreased substantially at the initial stage due to the requirement of aerobic heterotrophic metabolism. The highest DO content reached 6.55 and $8.57 \mathrm{mg} \mathrm{L}^{-1}$ in PFS systems B and $\mathrm{C}$ compared to $3.84 \mathrm{mg} \mathrm{L}^{-1}$ in system A. As shown in Fig. 2c), photosynthesis increases the $\mathrm{pH}$ via consumption of $\mathrm{CO}_{2}$ and $\mathrm{HCO}_{3}^{-}[10]$. The $\mathrm{pH}$ profile in PFS systems $\mathrm{B}$ and $\mathrm{C}$ increased substantially, which profited from the growing algae via PFS. In contrast, the $\mathrm{pH}$ range of system $\mathrm{A}(6.98-7.53)$ was lower than that of system B (7.46-7.78) and system C (7.50-8.15). PFS contributed to algae growth, thus facilitating the increase of DO and $\mathrm{pH}$ in HRAP. With the increasing PFS amount, the growing algae facilitated photosynthesis and higher $\mathrm{DO}$ content and $\mathrm{pH}$ value was obtained.

Fig. 3 shows the profiles of DCOD, DRP, and $\mathrm{NH}_{4}-\mathrm{N}$ in HRAP. DCOD value gradually decreased with HRT in three systems (Fig. 3a). Pollutant removal

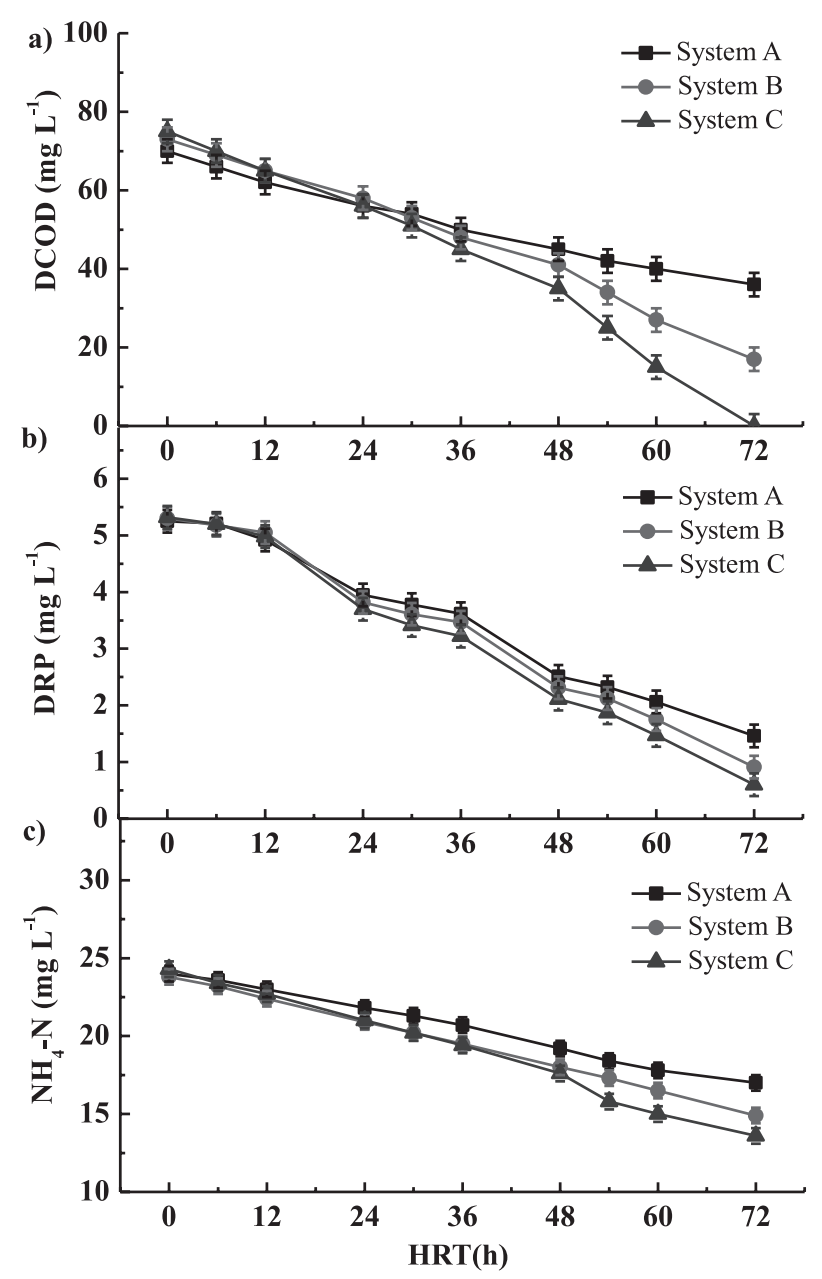

Fig. 3. Profiles of DCOD a), DRP b), and $\mathrm{NH}_{4}-\mathrm{N}$ c) in HRAP.

performance of the three systems was presented in Table 1. As presented in Table 1, PFS systems B and C (76.7\% and $99.0 \%$ ) had the capacity to remove DCOD more efficiently than system A (48.6\%), which was ascribed to aerobic degradation of DCOD via algal photosynthesis aeration. The increasing PFS amount contributed to further improvement of DCOD reduction. Consequently, DCOD removal in system $\mathrm{C}$ was significantly higher than that of system $B(p<0.01)$.

Ammonia and phosphate may be nutrient sources for algae [11]. Phosphorus removal was improved by algae-induced chemical precipitation and assimilation [12]. DRP value gradually decreased in three systems (Fig. 3b). PFS systems B and C showed better DRP removal performances of $82.8 \%$ and $88.5 \%$ (Table 1), which indicated that PFS were conductive to phosphorus assimilation by facilitating algae biomass. Additionally, chemical precipitation of phosphorus contributed to DRP elimination due to the elevated $\mathrm{pH}$ in PFS systems $\mathrm{B}$ and $\mathrm{C}$. With the increasing PFS amount, system C exhibited higher DRP removal than system $\mathrm{B}$. The main component of TP in the influent was DRP, hence the tendency of TP removal was consistent with the DRP profile in three systems. The highest TP elimination was observed in system $\mathrm{C}$. 
Table 1. Pollutant removal performance of the three systems.

\begin{tabular}{|c|c|c|c|c|}
\hline Parameter & Influent (mg L-1 $)$ & System & Effluent (mg L-1) & Removal (\%) \\
\hline \multirow{3}{*}{$\mathrm{NH}_{4}-\mathrm{N}$} & \multirow{3}{*}{$23.8 \pm 1.0$} & $\mathrm{~A}$ & $17.0 \pm 0.5$ & $29.2 \pm 2.0$ \\
\hline & & B & $14.9 \pm 0.5$ & $37.4 \pm 2.0$ \\
\hline & & $\mathrm{C}$ & $13.6 \pm 0.5$ & $44.0 \pm 2.0$ \\
\hline \multirow{3}{*}{$\mathrm{TN}$} & \multirow{3}{*}{$25.0 \pm 1.2$} & A & $18.4 \pm 0.8$ & $27.0 \pm 2.0$ \\
\hline & & $\mathrm{B}$ & $16.1 \pm 0.8$ & $36.9 \pm 2.0$ \\
\hline & & $\mathrm{C}$ & $14.5 \pm 0.8$ & $42.3 \pm 2.0$ \\
\hline \multirow{3}{*}{ DRP } & \multirow{3}{*}{$5.22 \pm 0.5$} & A & $1.46 \pm 0.2$ & $72.1 \pm 1.0$ \\
\hline & & $\mathrm{B}$ & $0.91 \pm 0.2$ & $82.8 \pm 1.0$ \\
\hline & & $\mathrm{C}$ & $0.60 \pm 0.2$ & $88.5 \pm 1.0$ \\
\hline \multirow{3}{*}{$\mathrm{TP}$} & \multirow{3}{*}{$5.58 \pm 0.5$} & A & $1.63 \pm 0.2$ & $70.8 \pm 1.0$ \\
\hline & & B & $1.13 \pm 0.2$ & $80.4 \pm 1.0$ \\
\hline & & $\mathrm{C}$ & $0.78 \pm 0.2$ & $86.1 \pm 1.0$ \\
\hline \multirow{3}{*}{ DCOD } & \multirow{3}{*}{$70.0 \pm 5.0$} & $\mathrm{~A}$ & $36.0 \pm 3.0$ & $48.6 \pm 3.0$ \\
\hline & & $\mathrm{B}$ & $17.0 \pm 3.0$ & $76.7 \pm 3.0$ \\
\hline & & $\mathrm{C}$ & $1.0 \pm 1.0$ & $99.0 \pm 1.0$ \\
\hline
\end{tabular}

Algal assimilation represents the direct nitrogen removal mechanism while ammonia volatilization causes indirect nitrogen removal [13]. Higher retention time enhanced $\mathrm{NH}_{4}-\mathrm{N}$ removals (Fig. 3c). PFS systems $\mathrm{B}$ and $\mathrm{C}$ were significantly more effective in $\mathrm{NH}_{4}-\mathrm{N}$ removal than system $\mathrm{A}(\mathrm{p}<0.01)$, which could be attributed to the algae growing more actively in HRAP with PFS. Furthermore, ammonia volatilization contributed to $\mathrm{NH}_{4}-\mathrm{N}$ elimination due to the elevated $\mathrm{pH}$ in PFS systems $\mathrm{B}$ and $\mathrm{C}$. With the increasing PFS amount, reduction in $\mathrm{NH}_{4}-\mathrm{N}$ was more significant in system $\mathrm{C}$, where the algae were most abundant $(p<0.01)$. The tendency of TN removal was in accordance with the drop of $\mathrm{NH}_{4}-\mathrm{N}$. The highest TN elimination was also observed in system C.

\section{Conclusions}

PFS provided growing sites and large interfaces conducive to algae growth and the occurrence of biochemical reaction, which improved algae biomass and pollutant removal performance of HRAP systems under cold climate. Better removal performance was obtained in PFS systems for algae flourishing growth. The increasing PFS amount in HRAP efficiently promoted the removal of organics and nutrients. This study demonstrated the application prospect of costeffective PFS for algae growth, which gave an effective solution for the dilemma of low algae biomass in HRAP in a cold climate.

\section{Acknowledgements}

This study was supported by the National Natural Science Foundation of China (grant Nos. 51809162 and 51679041), the Fundamental Research Funds for the Central Universities (grant No. 18D111310) and Shanghai Committee of Science and Technology, China (grant No. 16ZR1414800).

\section{Conflict of Interest}

The authors have not declared any conflict of interest.

\section{References}

1. MEHRABADIA., CRAGGS R., FARIDM.M. Wastewater treatment high rate algal ponds (WWT HRAP) for lowcost biofuel production. Bioresour. Technol. 184, 202, 2015.

2. LV J.P., GUO J.Y., FENG J., LIU Q., XIE S.L. A comparative study on flocculating ability and growth potential of two microalgae in simulated secondary effluent. Bioresour. Technol., 205, 111, 2016.

3. SUTHERLAND D.L., HOWARD-WILLIAMS C., TURNBULL M.H., BROADY P.A., CRAGGS R.J. Enhancing microalgal photosynthesis and productivity in wastewater treatment high rate algal ponds for biofuel production. Bioresour.Technol., 184, 222, 2015.

4. SUTHERLAND D.L., TURNBULL M.H., CRAGGS R.J. Environmental drivers that influence microalgal species in fullscale wastewater treatment high rate algal ponds. Water Res., 124, 504, 2017. 
5. GLOWACKA N., GADUS J., SLOBODNIK J. Anaerobic digestion of microalgal biomass Acutodesmus dimorphus (Turpin) P. Tsarenko as a substrate for biogas production. Polish J. of Environ. Stud., 27 (4), 1497, 2018.

6. RAS M., STEYER J.-P., BERNARD O. Temperature effect on microalgae: a crucial factor for outdoor production. Rev. Environ. Sci. Biotechnol., 12, 153, 2013.

7. LIU K.-G., ABBASI A.R., AZADBAKHT A., HU M.L., MORSALI A. Deposition of silver nanoparticles on polyester fiber under ultrasound irradiations. Ultrason. Sonochem., 34, 13, 2017.

8. KESAANO M., SIMS R.C. Algal biomass based technology for wastewater treatment. Algal Res., 5 (1), 231, 2014.

9. DING Y., SONG X.S., WANG W., WANG Y.H. Effects of influent algae concentrations and seasonal variations on pollution removal performance in high-rate algae ponds. Polish J. of Environ. Stud., 27 (4), 1901, 2018.
10. PARK J.B.K., CRAGGS R.J. Wastewater treatment and algal production in high rate algal ponds with carbon dioxide addition. Water Sci. Technol., 61, 633, 2010.

11. MAMUN M., LEE S.-J., AN K.-G. Roles of nutrient regime and $\mathrm{N}: \mathrm{P}$ ratios on algal growth in 182 Korean agricultural reservoirs. Polish J. of Environ. Stud., 27 (3), $1175,2018$.

12. LIANG Z., LIU Y., GE F., XU Y., TAO N., PENG F., WONG M. Efficiency assessment and $\mathrm{pH}$ effect in removing nitrogen and phosphorus by algae-bacteria combined system of Chlorella vulgaris and Bacillus licheniformis. Chemosphere, 92 (10), 1383, 2013.

13. PARK J.B.K, CRAGGS R.J., SHILTON A.N. Wastewater treatment high rate algal ponds for biofuel production. Bioresour. Technol., 102, 35, 2011. 